\title{
Acúmulo de matéria seca e exigências nutricionais de plantas de alho provenientes de cultura de tecidos e de propagação convencional ${ }^{1}$.
}

\author{
Francisco Vilela Resende ${ }^{1}$, Valdemar Faquin², Rovilson José de Souza ${ }^{2}$, Vanderlei S. Santos ${ }^{2}$ \\ ${ }^{1}$ UNIMAR - Faculdade de Ciências Agrárias, C. Postal 554, 17.525-902 Marília - SP, E-mail: fresende-ca@ unimar.br; ${ }^{2}$ UFLA, C. Postal \\ 37, 37.200-000 Lavras - MG.
}

\begin{abstract}
RESUMO
Com o objetivo de estudar comparativamente a exigência nutricional de plantas de alho provenientes de cultura de tecidos e multiplicadas de forma convencional, foi conduzido um experimento sob condições de campo, no Setor de Olericultura da Universidade Federal de Lavras (MG). O experimento foi montado em delineamento de blocos casualizados com quatro repetições e esquema de parcelas subdivididas no tempo. Os tratamentos foram constituídos por plantas provenientes de cultura de tecidos (cultura de meristemas) e multiplicadas de forma convencional e sete épocas de avaliação: 30, 50, 70, 90, 110, 130, e 150 dias após o plantio. Em cada época foram coletadas seis plantas/parcela, avaliado o peso da matéria seca da parte aérea e do bulbo e determinadas as quantidades acumuladas de N, P, K, Ca, Mg, S, B, Zn, Cu, Mn e Fe em cada parte. De maneira geral a absorção de nutrientes acompanhou o crescimento da planta, em ambas as formas de multiplicação, sendo que o acúmulo foi mais intenso entre 70 e 110 dias na parte aérea e 90 e 150 dias no bulbo. Diferenças significativas no acúmulo de nutrientes entre as formas de multiplicação foram verificadas somente na fase que coincidiu com o máximo desenvolvimento da parte aérea e do bulbo. As plantas multiplicadas por via convencional mostraram maior exigência por nitrogênio, em relação ao potássio, que plantas provenientes de cultura de tecidos. As plantas obtidas por cultura de tecidos acumularam quantidades significativamente maiores de nutrientes do que as obtidas de forma convencional e as diferenças percentuais na época da colheita foram da seguinte magnitude: $\mathrm{Ca}$ $83,2 \%, \mathrm{~K}-77,8 \%, \mathrm{~S}-70,0 \%, \mathrm{Mg}-62,7 \%, \mathrm{P}-55,5 \%, \mathrm{~N}-16,0 \%, \mathrm{Fe}$ $-116,6 \%, \mathrm{Mn}-94,5 \%, \mathrm{Cu}-64,7 \%, \mathrm{Zn}-62,7 \%, \mathrm{~B}-57,3 \%$.
\end{abstract}

Palavras-chave: Allium sativum L., multiplicação "in vitro", crescimento, nutrição mineral.

\begin{abstract}
Dry matter accumulation and nutritional requirements of garlic planted with cloves obtained by tissue culture or produced directly on the field.
\end{abstract}

An experiment was conducted under field conditions with the objective of studying differences on nutrient uptake and dry matter accumulation, between garlic plants produced from cloves obtained by tissue culture and plants originated from cloves produced directly in the field. A randomized block design with four replications was used in the split-plot scheme. The treatments consisted of garlic plants obtained from tissue culture (meristem-tip culture) and from cloves produced in the field, evaluated $30,50,70,90,110,130$, and 150 days after planting. At each period, six plants/plot were collected and dry matter of both aerial part and bulb were evaluated. Accumulated amounts of N, P, K, Ca, Mg, S, B, Zn, Cu, Mn and Fe in the garlic plants were also determined. In general, the amount of nutrient uptake corresponded to the development of the plants in both propagation system. Nutrient uptake was more intense between 70 and 110 days in the aerial part of the plants, and 90 and 150 days in the bulb. Differences in nutrient uptake between these two multiplication systems were verified only at the maximum development of both aerial and bulb portions. Plants originated from field propagation required more nitrogen than potassium when compared to those previously propagated by tissue culture. Plants originated from tissue culture accumulated more nutrients than those obtained from cloves produced directty on the field. These differences in nutrient accumulation were observed at the harvesting time and were expressed as percentage: $\mathrm{Ca}$ $-83.2 \%, \mathrm{~K}-77.8 \%, \mathrm{~S}-70.0 \%, \mathrm{Mg}-62.7 \%, \mathrm{P}-55.5 \%, \mathrm{~N}-16.0 \%$, $\mathrm{Fe}-116.6 \%, \mathrm{Mn}-94.5 \%, \mathrm{Cu}-64.7 \%, \mathrm{Zn}-62.7 \%, \mathrm{~B}-57.3 \%$.
Keywords: Allium sativum L., “in vitro” multiplication, growth, mineral nutrition.

\section{(Aceito para publicação em 11 de agosto de 1999)}

\begin{abstract}
A produtividade brasileira de alho, 4,83 t/ha (IBGE, 1998), encontrase ainda muito abaixo da média mundial, principalmente se comparada a de países como Argentina (7,57 t/ha), China $(8,67)$, EUA $(12,17$ t/ha) e Egito $(24,47 \mathrm{t} / \mathrm{ha})(\mathrm{FAO}, 1998)$. Entretanto, quando conduzido em condições de clima e solo adequadas, $o$ alho chega a atingir, no Brasil, produtividades de até 12 t/ha (Blank et al.,1998). No Egito, em regiões de solos férteis a produtividade
\end{abstract}

chega a 30t/ha (Menezes Sobrinho, 1984), mostrando que a nutrição mineral adequada das plantas é um dos componentes de produção mais importantes para a cultura.

Tem sido mostrado que o alho é uma das hortaliças mais exigentes em nutrientes (Oliveira et al., 1971), inclusive em alguns micronutrientes como o $\mathrm{B}$ e o Zn, sendo necessário em muitos casos, a realização de adubações com os mesmos (Garcia et al., 1994). Entretan- to, muitas vezes, a nutrição mineral é um dos fatores que recebe menos atenção pelos produtores brasileiros, causando sérios prejuízos não só à produção, como também à conservação pós-colheita dos bulbos.

A extração de nutrientes pelo alho apresenta uma relação bastante direta com o crescimento e desenvolvimento da planta. O crescimento da cultura se acentua a partir dos 60 dias e cessa aos 120 dias após o plantio e a bulbificação

\footnotetext{
${ }^{1}$ Parte da tese de doutoramento do primeiro autor apresentada à Universidade Federal de Lavras (UFLA), Lavras - MG.
} 
inicia-se por volta dos 70 dias, intensificando-se entre 90 até 130 dias após o plantio (Zink, 1963; Silva et al., 1970). Estes autores mencionam ainda, que o acúmulo de nutrientes até os 45 dias é reduzido, sendo que o nitrogênio e o potássio são acumulados intensamente nos períodos subsequentes. Os demais macronutrientes são acumulados em menor quantidade, acompanhando a curva de crescimento. Os micronutrientes são acumulados ativamente, porém de forma inconstante, desde os primeiros dias da cultura. A partir dos 45 dias, o ferro é acumulado intensamente, destacando-se como o micronutriente acumulado em maior quantidade pelo alho. Os demais micronutrientes são acumulados em quantidades menores e com menor intensidade, contudo, destacam-se o zinco e o manganês, que apresentam um acúmulo elevado no período entre 120 a 135 dias (Silva et al.,1970). Algumas técnicas de cultura de tecidos, com destaque para cultura de meristemas, têm sido utilizadas com êxito, visando recuperar a sanidade de clones infectados por viroses de espécies multiplicadas vegetativamente como a batata, alho, moranguinho, batata-doce, mandioquinha-salsa, dentre outras. Sabe-se que a presença de vírus nas plantas ocasiona uma série de distúrbios nas funções da célula, afetando principalmente a síntese de proteínas, além da inibição da fotossíntese, transporte de assimilados, ação de reguladores de crescimento e redução da produção (Gibbs \& Harrison, 1979), sendo que muitas destas funções envolvem direta ou indiretamente a participação de nutrientes minerais. Na cultura do alho, a eliminação de alguns vírus pela cultura de meristema, tem proporcionado aumentos significativos no vigor vegetativo (Walkey \& Antill, 1989; Resende et al., 1995), na produtividade e qualidade dos bulbos (Walkey \& Antill, 1989; Barni \& Garcia 1994; Resende et al., 1995). Entretanto, a exigência nutricional do alho multiplicado por cultura de tecidos ainda é pouco conhecida.

O estudo do acúmulo e utilização de nutrientes em plantas provenientes de cultura de tecidos torna-se necessário visando adequar a exigência nutricional à recomendação de adubação desses materiais em lavouras comerciais. Neste sentido, este trabalho teve como objetivos estudar o acúmulo de matéria seca e a absorção de nutrientes por plantas de alho provenientes de cultura de tecidos, comparativamente ao mesmo material multiplicado de forma convencional.

\section{MATERIAL E MÉTODOS}

O experimento foi conduzido no campo, em área experimental do Setor de Olericultura do Departamento de Agricultura da Universidade Federal de Lavras (UFLA) em um Latossolo Roxo, cujas características químicas e físicas, analisadas de acordo com a metodologia da Embrapa (1979), foram as seguintes: $\mathrm{pH}=6,4, \mathrm{P}=14 \mathrm{mg} / \mathrm{dm}^{3}, \mathrm{~K}=148 \mathrm{mg} /$ $\mathrm{dm}^{3}, \mathrm{Ca}=41 \mathrm{mmolc} / \mathrm{dm}^{3}, \mathrm{Mg}=18$ mmolc/dm $\mathrm{dm}^{3}, \mathrm{Al}=1 \mathrm{mmolc} / \mathrm{dm}^{3}, \quad \mathrm{~V}$ $=75 \%$, matéria orgânica $=35 \mathrm{~g} / \mathrm{dm}^{3} \mathrm{e}$ areia, limo e argila, 210, 280 e 510 g/ $\mathrm{kg}$, respectivamente.

Utilizaram-se plantas da cultivar Gigante Roxão obtidas de duas formas de multiplicação, sendo que os tratamentos foram definidos em função da obtenção do material de plantio. O primeiro tratamento foi composto por bulbos não indexados para viroses, provenientes de cultura de tecidos (propagação "in vitro" através de meristemas), obtidos pelo Laboratório de Biotecnologia da UFLA. O segundo tratamento foi composto por bulbos de plantas multiplicadas de forma convencional na Embrapa Hortaliças, em Brasília DF.

Os tratamentos foram dispostos em delineamento de blocos casualizados, em um esquema de parcela subdividida no tempo, com quatro repetições. Foram coletadas seis plantas/parcela em intervalos pré-definidos de 20 dias, resultando em sete épocas de coletas: 30, 50, 70, 90, 110, 130 e 150 dias após o plantio.

As parcelas foram formadas por canteiros com 0,20 m de altura, 1,00 m de largura por 2,00 m de comprimento, com cinco fileiras de plantas no espaçamento de $0,20 \mathrm{~m}$ entre linhas e $0,10 \mathrm{~m}$ entre plantas. A área útil de cada parcela foi constituída pelas três fileiras centrais, descartando-se duas plantas na extremidade de cada fileira, resultando numa área de $0,9 \mathrm{~m}$.
O plantio foi realizado no dia 29/04/ 95, tomando-se o cuidado de utilizar bulbilhos de mesmo tamanho dentro de cada bloco. Após o plantio realizou-se uma aplicação em pré emergência com o herbicida Linuron, seguida pela adição de uma camada de $5 \mathrm{~cm}$ de cobertura morta composta por casca de arroz. Em função da alta infestação da área por plantas daninhas, foi feita uma segunda aplicação de Linuron em pós-emergência, aos 20 dias após a emergência das plantas de alho. Todos os demais tratos culturais foram realizados de acordo com as recomendações técnicas para a cultura na região.

As adubações foram realizadas de acordo com a análise química do solo e as recomendações da Comissão... (1989). Aplicaram-se $200 \mathrm{~kg} / \mathrm{ha}$ de $\mathrm{P}_{2} \mathrm{O}_{5}$ como superfosfato simples, $60 \mathrm{~kg} / \mathrm{ha}$ de $\mathrm{K}_{2} \mathrm{O}$ como cloreto de potássio, $50 \mathrm{~kg} / \mathrm{ha}$ de sulfato de magnésio, $15 \mathrm{~kg} / \mathrm{ha}$ de bórax e $10 \mathrm{~kg} / \mathrm{ha}$ de sulfato de zinco. Foram utilizados $105 \mathrm{~kg} / \mathrm{ha}$ de nitrogênio na forma de uréia, parcelado em $1 / 3$ no plantio, $1 / 3$ aos 45 e 1/3 aos 70 dias após o plantio.

As plantas coletadas foram lavadas em água corrente e enxaguadas em água destilada, separando-se a parte aérea (folhas + bainhas) do bulbo. As partes foram distribuídas em sacos de papel perfurados e colocadas em uma estufa com circulação forçada de ar temperatura de $\pm 70^{\circ} \mathrm{C}$, para secagem. Após a secagem, o material vegetal foi pesado para obtenção da produção de matéria seca, moído e analisado quimicamente para os macro e micronutrientes.

$\mathrm{O} \mathrm{N}$ foi determinado pelo método semi-micro-kjeldahl com digestão ácida a quente. O B foi determinado através do método colorimétrico da curcumina com digestão por via seca. Para os demais nutrientes foi utilizado a digestão nitríco-perclórica, sendo as concentrações no extrato determinadas: $\mathrm{P}$ - colorimetria; $\mathrm{K}$ - fotometria de chama; S - turbidimetria e o $\mathrm{Ca}, \mathrm{Mg}, \mathrm{Fe}$, $\mathrm{Zn}, \mathrm{Cu}$ e $\mathrm{Mn}$ por espectrofotometria de absorção atômica (Malavolta et al., 1989). A quantidade de nutrientes acumulada pelo alho foi calculada com base no teor dos mesmos nos tecidos da parte aérea e bulbos e na produção de matéria seca dessas partes 


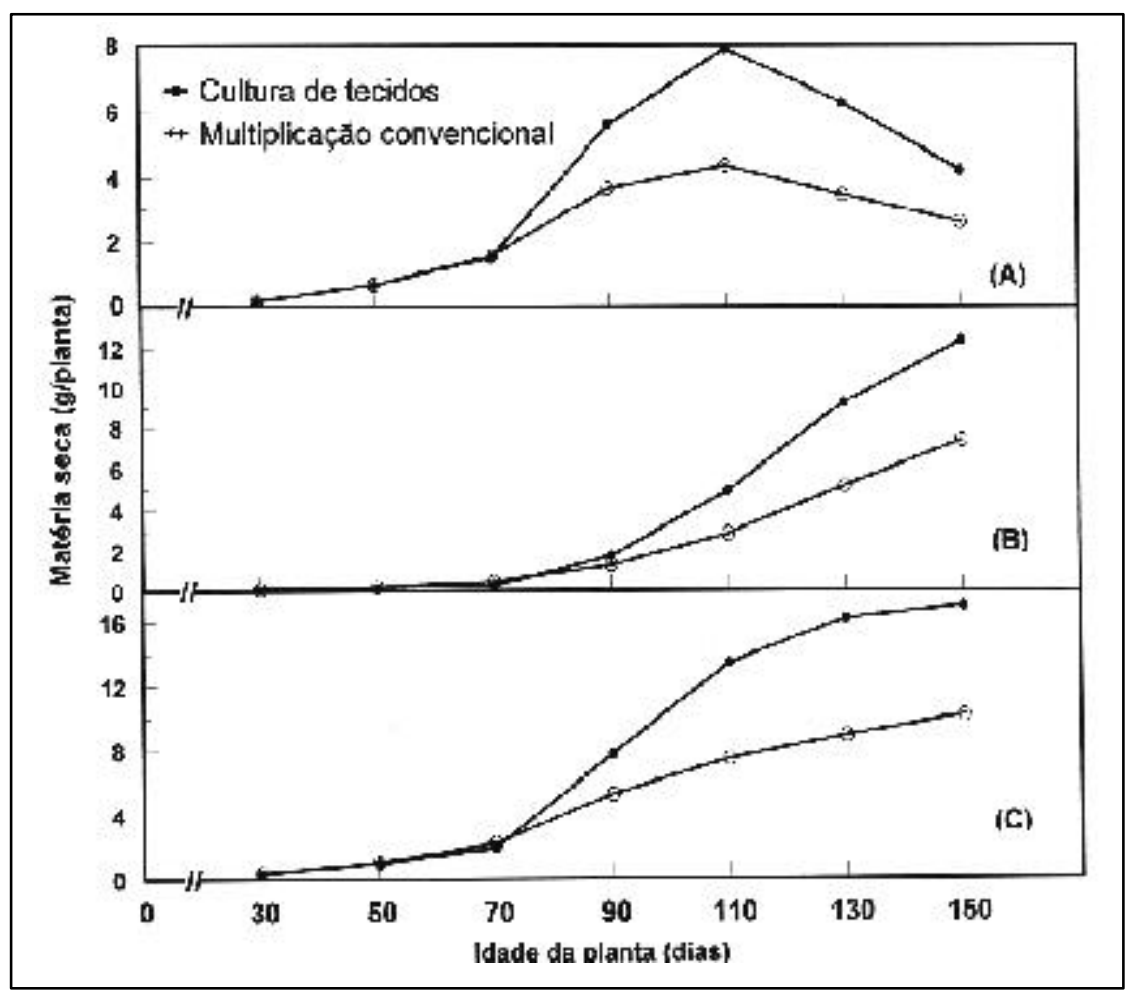

Figura 1. Produção de matéria seca em função da idade da planta, pela parte aérea (A), bulbo (B) e parte aérea + bulbo (C) de alho proveniente de cultura de tecidos e de multiplicação convencional. Lavras, UFLA, 1995.
Os dados obtidos foram submetidos aos testes de Lilliefors e Barttlet para verificar, respectivamente, o ajuste aos critérios de normalidade e homogeneidade exigidos para a análise de variância (Little \& Hills, 1978). As diferentes formas de multiplicação foram comparadas quanto ao acúmulo de matéria seca e nutrientes, em cada época de amostragem, pelo teste $\mathrm{F}$ (Gomes, 1990).

\section{RESULTADOS E DISCUSSÃO}

O crescimento das plantas, ilustrado pelo acúmulo de matéria seca, foi diminuto no período compreendido entre 30 e 70 dias para a parte aérea e 30 e 90 dias para o bulbo, para as duas formas de multiplicação (Figura 1). O acúmulo de matéria seca, considerando parte aérea + bulbo, mostrou-se significativamente $(\mathrm{p}<0,01)$ superior no período compreendido entre 90 e 150 dias para as plantas de cultura de tecidos e 110 e 150 dias para as plantas de propagação convencional, em relação às épocas anteriores.

A partir dos 90 dias para parte aérea e parte aérea + bulbo e, 110 dias para o bulbo, o acúmulo de matéria seca das plantas provenientes de cultura de tecidos

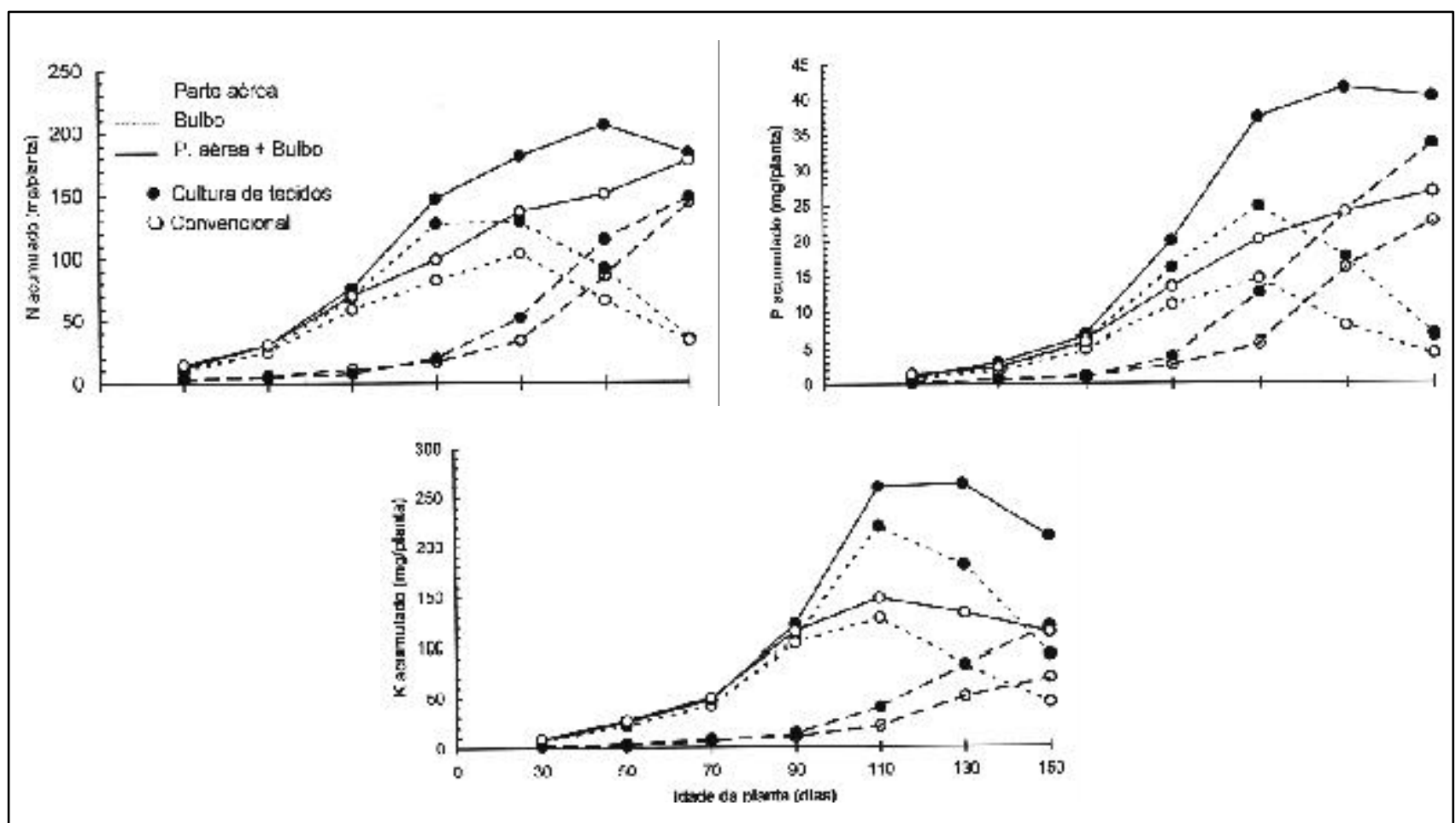

Figura 2. Acúmulo de nitrogênio, fósforo e potássio em função da idade da planta, pelo alho proveniente de cultura de tecidos e de multiplicação convencional. Lavras, UFLA, 1995. 
diferiu significativamente $(\mathrm{p}<0,01)$ do das plantas de propagação convencional.

A extração de nutrientes para ambas as formas de multiplicação (cultura de tecidos e convencional) acompanhou diretamente o crescimento das plantas, seguindo, de maneira geral, o comportamento observado em outros trabalhos (Zink, 1963; Silva et al.,1970 e Nascimento et al., 1996).

Os macronutrientes foram absorvidos em concentrações muito baixas até 50 dias após o plantio. O período de maior absorção do N, P, K, Mg e S foi verificado entre 50 e 110 dias (Figuras 2 e 3). O Ca, à exceção dos demais macronutrientes, teve sua extração intensificada somente a partir dos 70 dias (Figura 3).

$\mathrm{O}$ acúmulo de macronutrientes pelo bulbo foi muito pequeno nos primeiros 70 dias do ciclo. A partir dos 90 dias foram intensamente acumulados até o final do ciclo, com exceção do Ca que teve sua quantidade diminuída no bulbo a partir de 130 dias.

Entre os micronutrientes, o $\mathrm{Cu}$ apresentou um padrão de aumento relativamente constante no acúmulo pela parte aérea e parte aérea + bulbo desde os 30 dias após o plantio, em ambas as formas de multiplicação, enquanto os demais micronutrientes tiveram sua absorção aumentada a partir de 70 dias (Figuras 4 e 5). No bulbo o acúmulo de
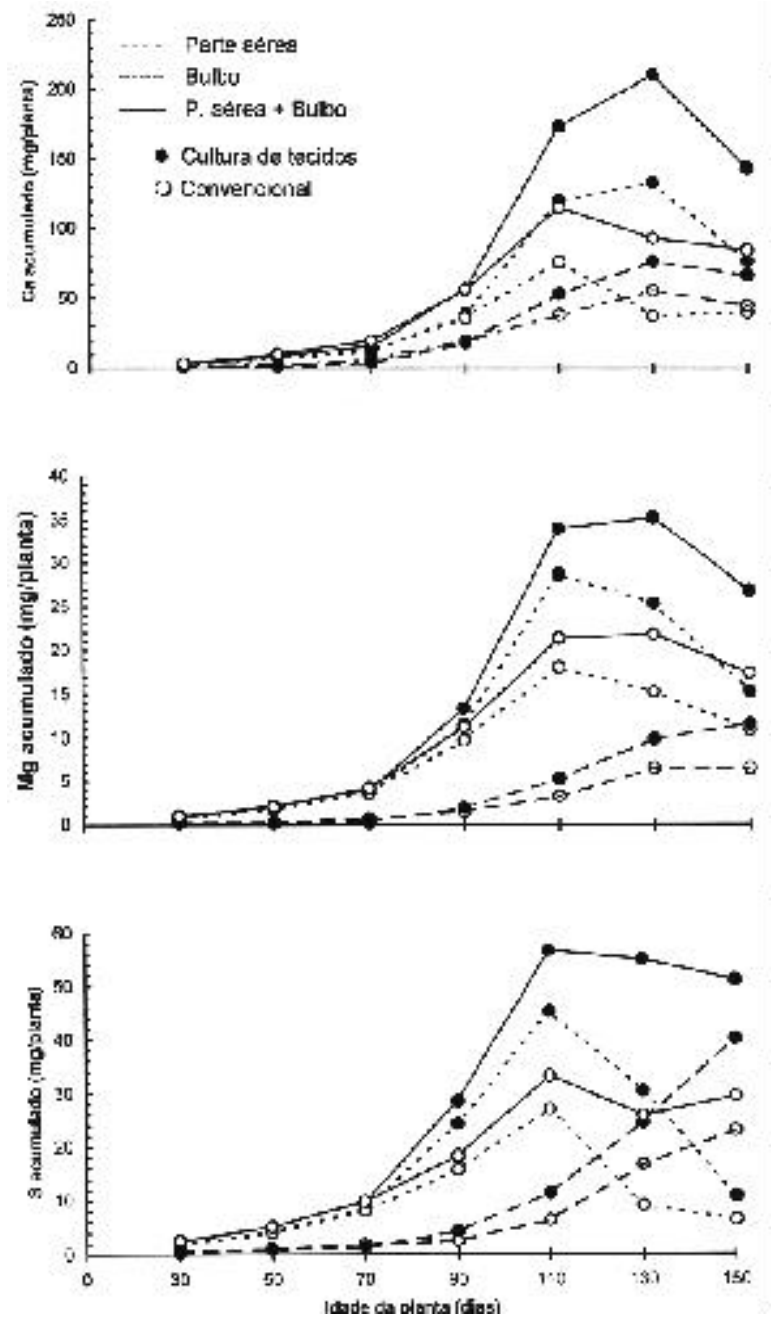

Figura 3. Acúmulo de cálcio, magnésio e enxofre em função da idade da planta pelo alho proveniente de cultura de tecidos e de multiplicação convencional. Lavras, UFLA, 1995.

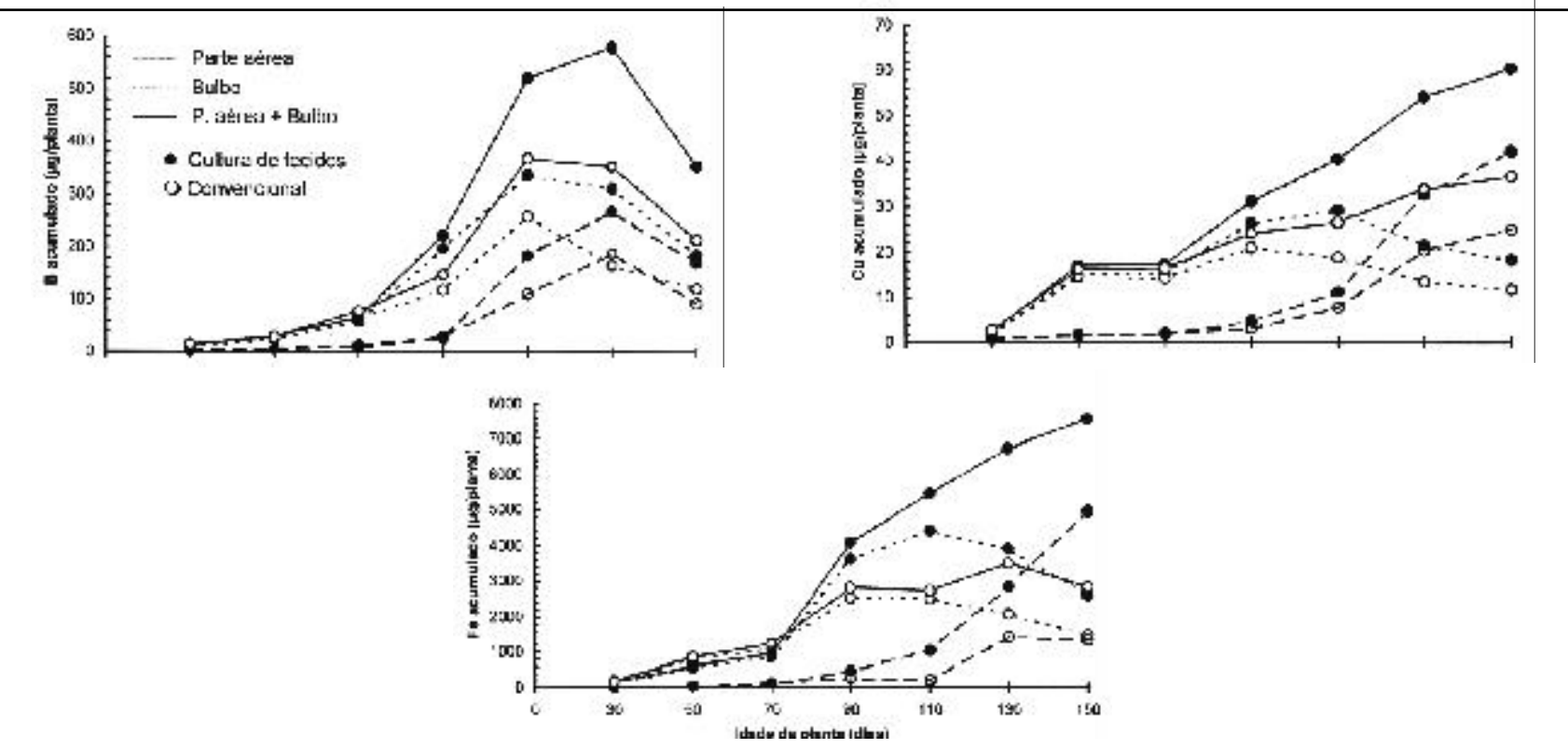

Figura 4. Acúmulo de Boro, Cobre e Ferro em função da idade da planta, pelo alho proveniente de cultura de tecidos e de multiplicação convencional. Lavras, UFLA, 1995. 


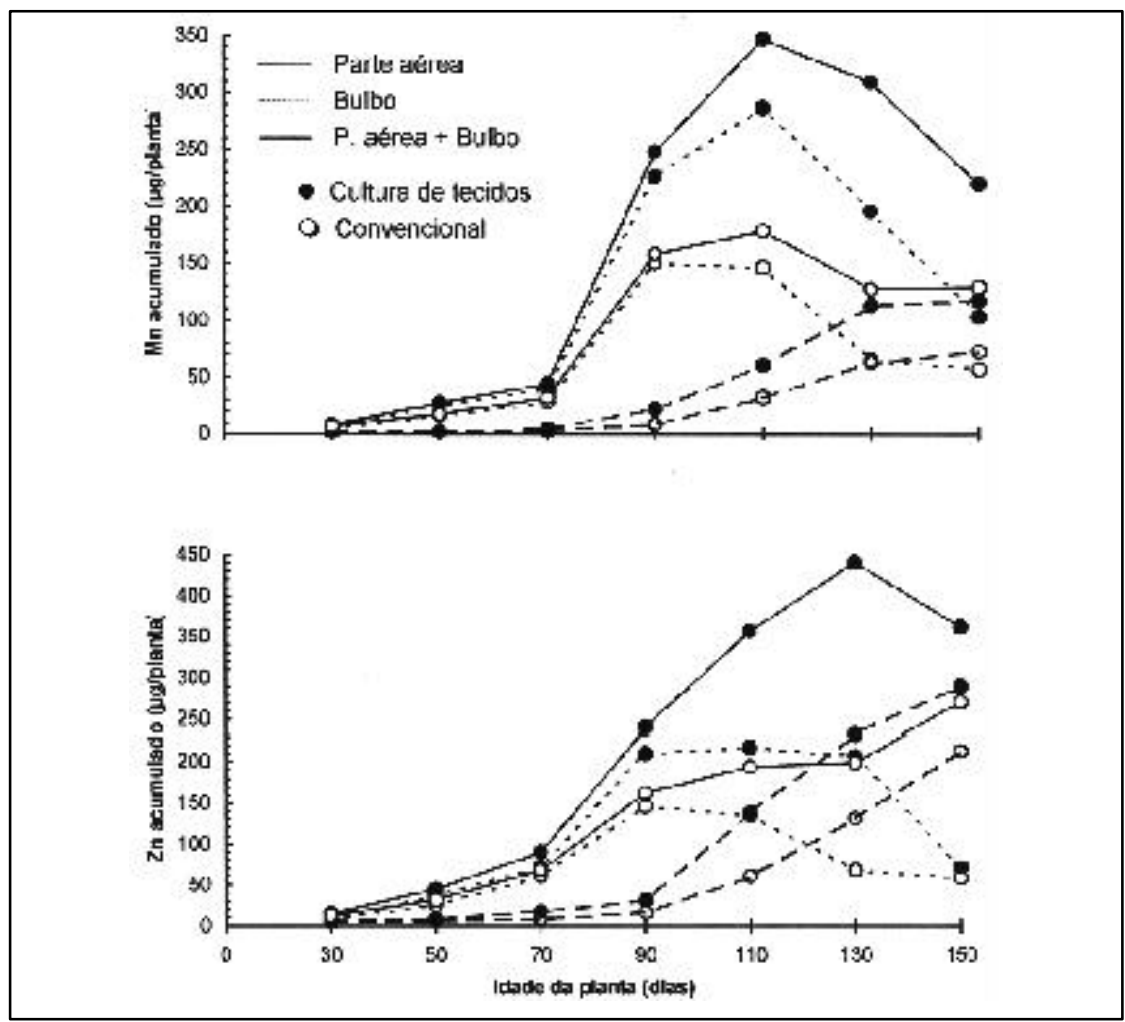

Figura 5. Acúmulo de Manganês e Zinco em função da idade da planta, pelo alho proveniente de cultura de tecidos e de multiplicação convencional. Lavras, UFLA, 1995.

micronutrientes foi pequeno até 90 dias, sendo intensamente acumulados a partir deste ponto até final do ciclo, à exceção do B que reduziu a quantidade acumulada depois de 130 dias após o plantio (Figura 4).

A partir de 110 dias verifica-se uma queda acentuada no acúmulo de nutrientes pela parte aérea da planta, marcando o início da senescência das folhas e desencadeando uma fase de intensa exportação dos nutrientes para o bulbo que se encontra em acelerado processo de crescimento. É interessante notar também que, parte da quantidade absorvida de alguns nutrientes como o $\mathrm{K}, \mathrm{Ca}, \mathrm{Mg}, \mathrm{B}$ e Mn foi perdida ou eliminada próximo ao final do ciclo da cultura. Este fato também foi observado no trabalho de Silva et al. (1970).

As diferenças estatísticas na absorção de nutrientes entre plantas oriundas de cultura de tecidos e multiplicadas pelo modo convencional aconteceram no período de maior acúmulo de matéria seca pelas plantas. Sabe-se que a multiplicação do vírus acompanha proporcionalmente o padrão de crescimento da planta, de forma que, se a planta intensifica o crescimento, o mesmo ocorre com a multiplicação do vírus (Gibbs \& Harrison, 1979). Portanto, o alho proveniente de cultura de tecidos, devido ao menor grau de infecção viral, apresentou crescimento significativamente superior ao multiplicado de forma convencional, traduzindo-se conseqüentemente em maior acúmulo de nutrientes.

Para o acúmulo de $\mathrm{N}(\mathrm{p}<0,05), \mathrm{P}$ $(p<0,01)$ e $S(p<0,01)$, foram observadas diferenças significativas entre as plantas oriundas das diferentes formas de multiplicação, a partir de 90 dias para a parte aérea e 110 dias para o bulbo, estendendo-se até 130 dias para o $\mathrm{N}$ e 150 dias para o $\mathrm{P}$ e $\mathrm{S}$. O K, $\mathrm{Mg}$ e $\mathrm{Ca}$ diferiram $(\mathrm{p}<0,01)$ desde os 110 dias para a parte aérea e para o bulbo.

$\mathrm{O} \mathrm{N}, \mathrm{K}$ e $\mathrm{Ca}$ foram os macronutrientes absorvidos em maior quantidade pela planta, tanto no alho proveniente de cultura de tecidos quanto no multiplicado de forma convencional. A quantidade máxima de $\mathrm{N}$ acumulada na parte aérea + bulbo por plantas provenientes de cultura de tecidos foi de $206,4 \mathrm{mg} /$ planta aos 130 dias e em plantas multiplicadas de forma convencional foi de $178,0 \mathrm{mg} /$ planta aos 150 dias. O K teve seu ponto máximo de acúmulo aos 130 dias (261,5 $\mathrm{mg} /$ planta) em plantas de cultura de tecidos e 110 dias (147,1 mg/planta) em plantas propagadas convencionalmente.

Em plantas de propagação convencional, verificou-se que a quantidade acumulada de $\mathrm{N}$ foi superior à de $\mathrm{K}$, como tem sido observado com frequiência em trabalhos com alho multiplicado de forma convencional (Zink, 1963, Silva et al.,1970; Büll \& Nakagawa, 1995). Entretanto, as plantas provenientes de cultura de tecidos, mostraram-se mais exigentes em $\mathrm{K}$ do que em N. Esta inversão pode estar relacionada à menor demanda de $\mathrm{N}$ em relação ao $\mathrm{K}$ pelas plantas de cultura de tecidos, em função da menor concentração viral em seus tecidos. As plantas multiplicadas pela via convencional, ao contrário, necessitam, proporcionalmente ao $\mathrm{K}$, de uma quantidade maior de $\mathrm{N}$ para atender à multiplicação do patógeno. Outra possível explicação para esta inversão está relacionada às quantidades de matéria seca significativamente superiores produzidas pelo alho de cultura de tecidos, tornando-o mais exigente em K. Este nutriente desempenha um papel fundamental em espécies que armazenam compostos orgânicos, como é o caso do alho, atuando no transporte de assimilados das folhas para os órgãos de reserva (Faquin, 1994).

As adubações de cobertura com N, realizadas aos 45 e 70 dias após o plantio, alteraram de forma significativa o padrão de absorção deste nutriente em plantas oriundas de cultura de tecidos e de propagação convencional, sendo que as primeiras responderam com maior intensidade às adubações de cobertura. A resposta à primeira cobertura refletiu-se mais significativamente na parte aérea, enquanto após a segunda cobertura, os bulbos mostraram maior intensidade de acúmulo. De 30 para 50 dias verificou-se um acréscimo no acúmulo de $\mathrm{N}$ de 190,0 e $110,9 \%$ na parte aérea e 25,1 e $83,3 \%$ no bulbo e entre 70 e 90 dias, 86,0 e $39,3 \%$ na parte aérea e 160,0 e $52,2 \%$ no bulbo, respectivamente, para plantas provenientes de cultura de tecidos e multiplicação convencional.

Quanto aos micronutrientes, foram observadas diferenças significativas 
$(p<0,01)$ entre plantas oriundas de cultura de tecidos e de multiplicação convencional desde de 50 dias e 90 dias para o $\mathrm{Zn}$ e o $\mathrm{Mn}$, respectivamente para parte aérea e bulbo, 90 e 110 dias para o B, 110 e 130 dias para o $\mathrm{Cu}$ e 90 dias em ambas as partes para o $\mathrm{Fe}$. Os micronutrientes absorvidos em maior quantidade foram o B com 580,4 e 368,9 $\mu \mathrm{g} /$ planta e o Fe com 7560,8 e $3490,5 \mu \mathrm{g} /$ planta, respectivamente, para o alho de cultura de tecidos e de multiplicação convencional. Silva et al. (1970), verificaram também em seu trabalho, como sendo estes, os micronutrientes absorvidos em maior quantidade pela cultura do alho.

Convertendo-se os dados experimentais para uma população de 400.000 plantas/ha, obteve-se as quantidades de macro e micronutrientes extraídas em um hectare (Tabela 1). Observou-se que o $\mathrm{Ca}, \mathrm{K}$ e $\mathrm{S}$ entre os macronutrientes e Fe e $\mathrm{Mn}$ entre os micronutrientes apresentaram as maiores diferenças de extração entre plantas provenientes de cultura de tecidos e propagação convencional.

A extração de nutrientes do solo pela planta está diretamente relacionada, além da intensidade de crescimento, também ao nível de produção da cultura. Cultivares de alho mais produtivas, têm-se mostrado também como mais exigentes em nutrientes (Bogatirenko, 1976; Minardi, 1978). Da mesma forma, o alho proveniente de cultura de tecidos tem-se mostrado superior ao mesmo material multiplicado de forma convencional em ensaios de produção a nível de campo, em níveis que variam desde $3,7 \%$ (Garcia et al. 1989) até 104,8\% (Resende et al., 1995).

Pode-se concluir que, de maneira geral, o acúmulo de nutrientes intensificou-se 90 dias após o plantio, acompanhando o crescimento da planta, em ambas as formas de multiplicação, sendo que as plantas obtidas por cultura de tecidos mostraram-se mais exigentes em nutrientes comparativamente àquelas multiplicadas de forma convencional.

A extração de macronutrientes, pelas plantas obtidas por ambas as formas de multiplicação, deu-se na seguinte ordem decrescente: $\mathrm{N}>\mathrm{K}>\mathrm{Ca}>\mathrm{S}>\mathrm{P}>\mathrm{Mg}$, à exceção do $\mathrm{K}$ para as plantas oriundas de cultura de tecidos, que foi o nutriente mais exigido. Para os micronutrientes, esta ordem foi: $\mathrm{Fe}>\mathrm{B}>\mathrm{Zn}>\mathrm{Mn}>\mathrm{Cu}$, para as duas formas de multiplicação.

Tabela 1. Quantidades totais de nutrientes extraídas pelo alho proveniente de cultura de tecidos e de multiplicação convencional. Lavras, UFLA, 1995.

\begin{tabular}{cccc}
\hline Nutriente & $\begin{array}{c}\text { Cultura de } \\
\text { tecidos }\end{array}$ & Convencional & Diferença (\%) \\
\hline \multicolumn{4}{c}{ Macronutrientes $\mathbf{( k g / h a )}$} \\
\hline $\mathrm{N}$ & 82,56 & 71,20 & 16,00 \\
$\mathrm{P}$ & 16,60 & 10,68 & 55,43 \\
$\mathrm{~K}$ & 104,60 & 58,84 & 77,77 \\
$\mathrm{~S}$ & 22,64 & 13,32 & 70,00 \\
$\mathrm{Mg}$ & 14,12 & 8,68 & 62,67 \\
$\mathrm{Ca}$ & 84,56 & 46,16 & 83,18 \\
\hline \multicolumn{4}{c}{ Micronutrientes (g/ha) } \\
\hline $\mathrm{B}$ & 232,16 & 147,56 \\
$\mathrm{Cn}$ & 176,40 & 108,44 & 57,33 \\
$\mathrm{Mn}$ & 24,24 & 14,72 & 62,67 \\
$\mathrm{Fe}$ & 139,00 & 71,48 & 64,67 \\
\hline
\end{tabular}

\section{AGRADECIMENTOS}

Ao pesquisador João Alves de Menezes Sobrinho (Embrapa Hortaliças) pelo fornecimento do alho-semente, possibilitando a realização deste trabalho. À Coordenadoria de Aperfeiçoamento de Pessoal de Ensino Superior (CAPES) pela concessão da bolsa de doutorado e à Fundação de Amparo a Pesquisa de Minas Gerais (FAPEMIG) pelo apoio financeiro.

\section{LITERATURA CITADA}

BARNI, V.; GARCIA, A. Comportamento do alho Quitéria isento do vírus do estriado amarelo em diferentes condições de cultivo. Hortisul, Pelotas, v. 3, n. 3, p. 15-19, 1994.

BLANK, A.F.; PEREIRA, A.J.; SOUZA, R.J. de; ARRIGONI-BLANK, M. F. Competição de cultivares de alho não vernalizado visando à maior produção quantitativa e qualitativa para região de Lavras (MG). Ciência e Agrotecnologia, Lavras, v. 22, n. 1, p. 5-12, 1998.

BOGATIRENKO, A.K. The effects of organic and mineral fertilizers on garlic yield and nutrient removal from the soil. Ovochivniststvo $i$ Bashtannitsvo, v. 20, p. 21-27, 1975. In: Horticultural Abstracts, v. 46, p. 9, 1976. (Abstract 8378).

BÜLL, L.T.; NAKAGAWA, J. Desenvolvimento e produção de bulbos e absorção de nutrientes na cultura do alho vernalizado em função das relações cálcio:magnésio no solo. Revista Brasileira de Ciência do Solo, Campinas, v. 19, n. 3, p. 409-415, 1995.
COMISSÃO DE FERTILIDADE DO SOLO DE MINAS GERAIS. Recomendações para uso de corretivos e fertilizantes em Minas Gerais; 4a aproximação. Lavras, 1989. 76 p.

EMPRESA BRASILEIRA DE PESQUISA AGROPECUÁRIA. Serviço Nacional de Levantamento de Solos. Manual de métodos de análise do solo. Rio de Janeiro: EMBRAPA, 1979. n.p.

FAO (Roma, Italy). Agricultural production, primary crops - garlic. Disponível em http:// www.fao.org. Consultado em 11 de nov. de 1998.

FAQUIN, V. Nutrição Mineral de Plantas. Lavras:ESAL/FAEPE, 1994. 227 p.

GARCIA, D.C.; DETTMANN, L.A.; BARNI, V.; RIBEIRO, N. Resposta do alho à adubação com boro, zinco e cobre. Hortisul, Pelotas, v. 3, n. 1, p. 20-25, 1994.

GARCIA, A.; PETERS, J.A.; CASTRO, L.A.S Formação de estoques pré-básicos de alho-semente e estudo da sensibilidade da cultura à infecção por vírus. Hortisul, Pelotas, v. 1, n. 1, p. 42-44, 1989.

GIBBS, A.; HARRISON, B. Plant Virology: the principles. New York: Buffer and Turner, 1979. 292 p.

IBGE (Rio de Janeiro, RJ). Informações estatísticas, produção agrícola - alho. Disponível em http://www.sidra.ibge.gov.br. Consultado em 11 de nov. de 1998.

LITTLE, T.M.; HILLS, F.J. Agricultural Experimentation, New York: John Willey and sons, 1978. $350 \mathrm{p}$.

MALAVOLTA, F.; VITTI, G.C.; OLIVEIRA, S.A. de. Avaliação do estado nutricional das plantas: princípios e aplicações. Piracicaba: Associação Brasileira para Pesquisa da Potassa e do Fosfato, 1989. 201 p.

MENEZES SOBRINHO, J.A. Cultivo do alho (Allium sativum L.), Brasília:EMBRAPACNPH, 1984. (EMBRAPA-CNPH. (Instruções técnicas, n. 2)) 
MINARDI, H.R.G. Effect of clove size, spacing, fertilizers, and lime on yield and nutrient content of garlic (Allium sativum L.). New Zealand Journal of experimental Agriculture, v. 6, n. 2, p. 139-143, 1978.

NASCIMENTO, V.M.; SENO, S.; DELAVALE, F.G. Produção e absorção de nutrientes em duas cultivares de alho (Allium sativum L.) na região de Ilha Solteira, SP. Horticultura Brasileira, Brasília, v. 14, n. 1, p. 102. 1996.
GOMES, F.P. Curso de estatística experimental. Piracicaba:Nobel, 1990. 468 p.

OLIVEIRA, G.D.; FERNANDEZ, P.D.; SARRUGE, J.R.; HAAG, H.P. Nutrição mineral de hortaliças XIII. Extração dos macronutrientes pelas hortaliças. $O$ Solo, Piracicaba, v. 63, n. 1, p. 7-12.1971.

RESENDE, F.V.; SOUZA, R.J.; PASQUAL, M Comportamento em condições de campo de clones de alho obtidos por cultura de meristema. Horticultura Brasileira, Brasília, v. 13, n. 1, p. 44-46, 1995.
SILVA, N.; OLIVEIRA, G.R.; VASCONCELOS, E.F.C.; HAAG, H.P. Absorção de nutrientes pela cultura do alho. $O$ Solo, Piracicaba, v. 62, n. 1, p. 8-17. 1970.

WALKEY, D.G.A.; ANTILL, D.N. Agronomic evaluation of virus-free and virus-infected garlic (Allium sativum L.). Journal of Horticultural Science, v. 64, n. 13, p. 53-60, 1989.

ZINK, K.F.W. Rate of growth and nutrient absorption of late garlic. Proceedings of American Society of Horticultural Science, v. 83, p. 579-584.1963. 